\title{
Intersphincteric Approach for Deep Postanal Sepsis
}

\author{
Do Sun Kim \\ Department of Surgery, Daehang Hospital, Seoul, Korea
}

See Article on Page 55-59

The article is interesting enough to draw the attention of surgeons because the intersphincteric approach for the treatment of deep postanal sepsis seems to be a novel procedure. The deep postanal space is clinically significant because it can provide routes for the extension of an infection when a cryptoglandular infection enters into this potential space, complicating treatment, potentially leaving a severe deformity and possibly compromising continence when conventional treatment is used $[1,2]$.

Several techniques, such as advancement flap, a fistula plug (AFP) and stem-cell injection, have been attempted to treat complex fistulas $[3,4]$. However, they have the limitations of technical difficulty, unsatisfactory results and high cost. Ligation of inter sphincteric fistula tract (LIFT) has recently been introduced to overcome these limitations [5]. LIFT is technically simple and shows reproducible results with relatively satisfactory success rates. However, LIFT also has limitations in terms of indications. LIFT is not feasible if a fistula has a blind end or an accompanying abscess. Further, most studies were performed on patients with a trans-sphincteric fistula. There have been few reports on more complicated fistulas [6].

The authors' novel approach has the obvious advantages of its being a one-stage procedure and its being capable of preserving an intact sphincter, regardless of the presence of an abscess. However, this approach doesn't seem to be an entirely novel procedure, but a modification of LIFT in general. Technical differences are suturing the fistulous tract of the internal sphincter side instead of ligation and using suction drainage. There are also differences in

Correspondence to: Do Sun Kim, M.D.

Department of Surgery, Daehang Hospital, 2151 Nambusunhwan-ro, Seocho-gu, Seoul 137-820, Korea

Tel: +82-2-6388-8114, Fax: +82-2-6388-8673

E-mail: dskim1@daehang.com

(C) 2013 The Korean Society of Coloproctology

This is an open-access article distributed under the terms of the Creative Commons Attribution NonCommercial License (http://creativecommons.org/licenses/by-nc/3.0) which permits unrestricted noncommercial use, distribution, and reproduction in any medium, provided the original work is properly cited. terms of indications. The authors seem to have dealt with various conditions of infection, including abscesses, fistulas and fistulous conditions without an external opening.

In my opinion, the technical similarity, the differences in indications, and the small number of patients may prevent readers of this article from taking the results as a convincing outcome. There may be few surgeons who would try an excision of an infected gland by dissecting the intersphincteric plane when there is irrefutable evidence of deep postanal space abscess. This is because LIFT is not generally indicated when there is a simultaneous abscess. Technically, LIFT can be performed even in patients with a concurrent abscess if the fistulous tract in the intersphincteric space is identified. However, technical feasibility doesn't always mean a favorable outcome. I doubt we can overcome the limitations of LIFT by simply using suction drainage. Furthermore, I am not confident that we can predict the presence of fistulous tracts in the intersphincteric space. Of special concern, a fistulous tract may not be detected in an acute stage of infection and abscess $[7,8]$. Even in cases of simple perianal abscesses, a fistulotomy is not indicated when there is no identifiable internal opening [9]. When there is not an identifiable tract in the intersphincteric plane, there may be few options we can choose from.

Another concern is the huge difference in success rates between the primary- and the secondary-procedure groups. The authors reported a $70 \%$ success rate, which is similar to the reported rates of LIFT. However, the success rate for the secondary-drainage group (20\%) was much worse compared to that for the primaryprocedure group (91\%). The authors' explanation that infected glands might have been obliterated after the drainage procedure doesn't sound reasonable. The difference in the success rates more likely resulted from the small number of patients or possibility some patients being more suitable for this procedure.

In short, interpreting the results and predicting the feasibility of the procedure is very difficult because of the small number of patients. There may be some patients who are good candidates for this new procedure. A large-scale study seems to be necessary to confirm the effectiveness of this procedure and to refine the indications for this procedure. 


\section{REFERENCES}

1. Browder LK, Sweet S, Kaiser AM. Modified Hanley procedure for management of complex horseshoe fistulae. Tech Coloproctol 2009;13:301-6.

2. Pezim ME. Successful treatment of horseshoe fistula requires deroofing of deep postanal space. Am J Surg 1994;167:513-5.

3. Champagne BJ, O'Connor LM, Ferguson M, Orangio GR, Schertzer ME, Armstrong DN. Efficacy of anal fistula plug in closure of cryptoglandular fistulas: long-term follow-up. Dis Colon Rectum 2006;49:1817-21.

4. Garcia-Olmo D, Herreros D, Pascual I, Pascual JA, Del-Valle E, Zorrilla J, et al. Expanded adipose-derived stem cells for the treatment of complex perianal fistula: a phase II clinical trial. Dis Colon Rectum 2009;52:79-86.
5. Rojanasakul A. LIFT procedure: a simplified technique for fistulain-ano. Tech Coloproctol 2009;13:237-40.

6. Tan KK, Tan IJ, Lim FS, Koh DC, Tsang CB. The anatomy of failures following the ligation of intersphincteric tract technique for anal fistula: a review of 93 patients over 4 years. Dis Colon Rectum 2011;54:1368-72.

7. Tan KK, Liu X, Tsang CB, Koh DC. Identification of the internal anal opening and seton placement improves the outcome of deep postanal space abscess. Colorectal Dis 2012 Oct 26 [Epub]. http:// dx.doi.org/10.1111/codi.12076.

8. Zbar AP, Armitage NC. Complex perirectal sepsis: clinical classification and imaging. Tech Coloproctol 2006;10:83-93.

9. Ramanujam PS, Prasad ML, Abcarian H, Tan AB. Perianal abscesses and fistulas: a study of 1023 patients. Dis Colon Rectum 1984;27:593-7. 